\title{
Analisis Kesulitan Guru Sekolah Dasar dalam Pembelajaran Matematika di SDN 012 Kp. Panjang Airtiris
}

\author{
Adityawarman Hidayat ${ }^{1}$, Zulhendri ${ }^{2}$, Bunga Casandra ${ }^{3}$ \\ 1, 2,3 Program Studi Pendidikan Matematika, Fakultas Ilmu Pendidikan, Universitas Pahlawan Tuanku Tambusai, \\ Jl. Tuanku Tambusai No 23, Bangkinang, Indonesia \\ adityawarmanhidayat@ymail.com
}

\begin{abstract}
The difficulty of elementary school math teachers in math learning is that teachers are difficult at planning the mathematical learnig process, teachers are difficult at carrying out the mathematical learning process and teachers are difficult at communicating with students during math study. The purpose of this study is to know the extent of the planning of mathematics learning teachers have done, the performance of mathematics learning by teachers as well as the communication process between teachers and the student in the math class. The type of research used is qualitative descriptive analysis of data and information obtained from research for later interpretation according to the fact that in planning the learning process, the most frequent difficulty is determining the learning media by as much as $(25 \%)$ and then creating teaching methods $(18,75 \%)$. The next challenge to the mathematical learning process, the most frequent difficulty is to motivate students to ask the question of a magnitude $(44,44 \%)$. The last difficulty is in communicating with the students. The most frequent challenge is to stimulate a students interest in math lessons by $(42,85 \%)$. Should a math teacher have special skills in order to increase the students interest in math and not impress the monotonous in the matter of speaking.
\end{abstract}

Keyword : Elementary school teacher difficulties, Mathematical learning

\begin{abstract}
Abstrak
Kesulitan guru matematika di Sekolah Dasar dalam pembelajaran matematika adalah guru sulit dalam merencanakan proses pembelajaran matematika, guru sulit dalam melaksanakan proses pembelajaran matematika dan guru sulit dalam berkomunikasi dengan siswa pada saat pembelajaran matematika berlangsung. Tujuan penelitian ini untuk mengetahui sejauh mana perencanaan pembelajaran matematika yang telah dilakukan guru, bagaimana pelaksanaan pembelajaran matematika oleh guru maupun proses komunikasi antara guru dengan siswa dalam pembelajaran matematika dikelas. Jenis penelitian yang digunakan adalah deskriptif kualitatif, yaitu menganalisa data-data dan informasi yang didapat dari hasil penelitian untuk kemudian diinterpretasi sesuai dengan kenyataannya. Hasil penelitian menunjukkan bahwa dalam merencanakan proses pembelajaran, kesulitan yang paling sering terjadi adalah menentukan media pembelajaran yaitu sebesar (25\%) dan selanjutnya menetukan metode mengajar yaitu sebesar (18,75\%). Kesulitan berikutnya pada proses pembelajaran matematika, kesulitan yang paling sering terjadi adalah memotivasi siswa untuk bertanya yaitu sebesar (44,44\%). Kesulitan yang terakhir adalah dalam berkomunikasi dengan siswa. Kesulitan yang paling sering terjadi adalah merangsang minat siswa terhadap pelajaran matematika yaitu sebesar $(42,85 \%)$. Hendaknya seorang guru matematika seharusnya mempunyai keterampilan khusus agar bisa menambah minat siswa terhadap matematika dan tidak terkesan monoton dalam menyampaikan materi.
\end{abstract}

Kata kunci: Kesulitan Guru Sekolah Dasar, Pembelajaran Matematika

Copyright (c) 2019 Adityawarman Hidayat, Zulhendri, Bunga Casandra

Corresponding author: Ria Kasanova

Email Address: adityawarmanhidayat@ymail.com (Jl. Tuanku Tambusai No 23, Bangkinang, Indonesia)

Received 09 September 2021, Accepted 06 October 2021, Published 06 October 2021

\section{PENDAHULUAN}

Kesulitan guru matematika di Sekolah Dasar dalam pembelajaran matematika adalah masalah penting yang harus mendapatkan perhatian oleh semua pihak terutama pada guru matematika itu sendiri. Kesulitan tersebut dibagi tiga hal yaitu guru sulit dalam merencanakan proses pembelajaran matematika, guru sulit dalam melaksanakan proses pembelajaran matematika dan guru sulit dalam 
berkomunikasi dengan siswa pada saat pembelajaran matematika berlangsung. Selama ini, matematika dianggap sulit oleh siswa dan sangat menakutkan. Hal ini terjadi karena ketidakmampuan guru dalam menyajikan pembelajaran matematika secara menarik dan menyenangkan sehingga pembelajaran matematika itu dianggap sulit oleh siswa. Perbaikan yang perlu diperhatikan adalah dengan melihat kembali perencanaan, proses dan perjalanan pembelajaran matematika dikelas.

Berbagai persoalan tentang pembelajaran matematika, nampaknya posisi guru menjadi sentral. Hal ini juga disinyalir oleh Prof. Dr. Santoso Muwarni, yang menekankan keberhasilan pembelajaran matematika pada sumber daya manusia yaitu guru sebagai perancang proses pembelajaran. Guru juga sebagai motivator, pendidik, pembimbing yang mempunyai peran penting dalam mengarahkan anak didiknya untuk mampu dan mengaktualisasikan dalam kehidupan nyata tentang pelajaran yang dapat di sekolah. Adanya kesan guru matematika umumnya angker menjadi krirtik tajam bagi guru matematika yang harus diperhatikan. Tujuan penelitian ini untuk mengetahui sejauh mana perencanaan pembelajaran matematika yang telah dilakukan guru, bagaimana pelaksanaan pembelajaran matematika oleh guru maupun proses komunikasi antara guru dengan siswa dalam pembelajaran matematika dikelas.

\section{METODE}

Jenis penelitian yang digunakan adalah deskriptif kualitatif, yaitu menganalisa data-data dan informasi yang didapat dari hasil penelitian untuk kemudian diinterpretasi sesuai dengan kenyataannya. Penelitian dilaksanakan di SDN 012 KP. Panjang Airtiris. Waktu pelaksanaan penelitian dilaksanakan di semester Ganjil tahun ajaran 2020/2021. Subjek dalam penelitian ini adalah Guru SDN 012 KP. Panjang Airtiris. Guru-guru SDN 012 KP. Panjang Airtiris diberikan angket yang akan diisi, mewawancarai dan kemudian memaparkan hasil-hasil yang didapat di lapangan. Data yang diperoleh baik dari wawancara maupun angket berupa data mentah, yang kemudian diolah melalui beberapa teknik yaitu kategorisasi dan perhitungan.

\section{HASIL DAN DISKUSI}

\section{Kesulitan dalam Merencanakan Proses Pembelajaran}

Mempersiapkan dan merencanakan proses pembelajaran matematika dengan baik dan benar merupakan salah satu kunci keprofesionalan seorang guru matematika. Seorang guru matematika hendaknya membuat peta tentang proses pembelajaran yang akan dilaksanakan dikelas. Fakta memperlihatkan bahwa salah satu kesulitan guru matematika dalam pembelajaran yaitu ketika merencanakan proses pembelajaran. Untuk lebih jelasnya, lihat tabel berikut. 
Tabel 1. Kesulitan Guru dalam Merencanakan Proses Pembelajaran Matematika

\begin{tabular}{|c|c|c|c|c|}
\hline No. & Kesulitan & Sebab & $\begin{array}{l}\text { Jumlah } \\
\text { (orang) }\end{array}$ & $\begin{array}{c}\text { Persentase } \\
(\%)\end{array}$ \\
\hline 1 & Membuat satuan pelajaran & $\begin{array}{l}\text { Kurang paham cara } \\
\text { membuat satpel }\end{array}$ & 1 & 6,25 \\
\hline 2 & Mendesain ruang belajar & $\begin{array}{l}\text { Siswa telalu banyak, } \\
\text { ruangan terlalu kecil }\end{array}$ & 3 & 18,75 \\
\hline 3 & $\begin{array}{l}\text { Menentukan media } \\
\text { Pembelajaran }\end{array}$ & $\begin{array}{ll}\text { 1. } & \text { Tidak terjangkau } \\
\text { siswa } \\
\text { 2. }\end{array}$ & 4 & 25 \\
\hline 4 & Menentukan prosedur penilaian & $\begin{array}{l}\text { Nilai untuk siswa yang } \\
\text { lemah }\end{array}$ & 3 & 18,75 \\
\hline 5 & $\begin{array}{l}\text { Menentukan buku matematika } \\
\text { pegangan sebagai sumber }\end{array}$ & $\begin{array}{ll}\text { 1. } & \begin{array}{l}\text { Daya serap anak } \\
\text { berbeda }\end{array} \\
\text { 2. } & \begin{array}{l}\text { Berubahnya } \\
\text { kurikulum }\end{array} \\
\end{array}$ & 2 & 12,5 \\
\hline 6 & Menentukan metode mengajar & $\begin{array}{l}\text { Tingkat intelegensi } \\
\text { berbeda }\end{array}$ & 3 & 18,75 \\
\hline \multicolumn{3}{|c|}{ Total } & 16 & 100 \\
\hline
\end{tabular}

Berdasarkan tabel di atas menunjukkan bahwa menentukan media pembelajaran merupakan kesulitan terbanyak yang dialami guru matematika. Hal ini terjadi karena terbatasnya sarana prasarana yang disediakan sekolah untuk menunjang proses pembelajaran (sebab ini mendapat jawaban terbanyak dari responden), disamping itu kesulitan tersebut juga karena media yang harganya tidak terjangkau oleh siswa (lihat tabel 5.2). Selanjutnya dari kesulitan dalam merencanakan proses pembelajaran berturut-turut adalah mendesain ruangan belajar, menentukan prosedur penilaian, serta menentukan metode mengajar. kesulitan ini disebabkan siswa dalam satu kelas berbeda-beda tingkat intelegensinya sehingga guru kesulitan dari mana memulai pembelajaran dan metode apa yang cocok untuk diterapkan dalam pembelajaran.

\section{Kesulitan dalam Melaksanakan Proses Pembelajaran}

Kesulitan dalam melaksanakan proses pembelajaran yang sering dialami guru matematika dalam melaksanakan proses pembelajaran dapat dilihat pada tabel berikut.

Tabel 2. Kesulitan Guru dalam Melaksanakan Proses Pembelajaran Matematika

\begin{tabular}{|c|l|l|c|c|}
\hline No & \multicolumn{1}{|c|}{ Kesulitan } & \multicolumn{1}{|c|}{ Sebab } & $\begin{array}{c}\text { Jumlah } \\
\text { (orang) }\end{array}$ & $\begin{array}{c}\text { Persentase } \\
(\mathbf{\%})\end{array}$ \\
\hline 1 & Mempraktekkan Metode & Kurang alat peraga & 3 & 33,33 \\
\hline 2 & $\begin{array}{l}\text { Respon dan Memotivasi } \\
\text { Siswa untuk Bertanya }\end{array}$ & $\begin{array}{l}\text { Tidak menguasai dasar } \\
\text { Matematika, Kurang } \\
\text { minat terhadap } \\
\text { Matematika, Siswa malu } \\
\text { dan takut, Materi terlalu } \\
\text { banyak }\end{array}$ & 4 & 44,44 \\
\hline 3 & Alokasi Waktu Belajar & $\begin{array}{l}\text { Banyaknya siswa dalam } \\
\text { 1 kelas }\end{array}$ & 1 & 11,11 \\
\hline
\end{tabular}




\begin{tabular}{|c|l|l|c|c|}
\hline 4 & $\begin{array}{l}\text { Mengetahui Kemampuan } \\
\text { Siswa Yang Berbeda }\end{array}$ & $\begin{array}{l}\text { Bekerjasama dalam } \\
\text { menjawab soal }\end{array}$ & 1 & 11,11 \\
\hline \multicolumn{2}{|c|}{ Total } & $\mathbf{9}$ & $\mathbf{1 0 0}$ \\
\hline
\end{tabular}

Tabel diatas menunjukkan bahwa kesulitan yang paling sering dialamai guru matematika adalah merangsang respon dan memotivasi siswa bertanya tentang materi yang telah disampaikan, kenyataan ini begitu tinggi karena ada 44,44\% responden menjawab hal itu. Adapun kesulitan selanjutnya adalah mempraktekkan metode mengajar. Hal ini disebabkan karena ketidakmampuan mengkolaborasikan alat peraga dalam metode mengajar yang digunakan, sehingga sebagian besar siswa merasa bingung dengan keberadaan alat peraga yang digunakan sehingga hasil belajar kurang maksimal. Adanya kesulitan yang terjadi di atas bukanlah sesuatu yang harus dipungkiri, semuanya harus dicari solusi guna meningkatkan kualitas dalam mengajar dan menjadi guru yang profesional.

\section{Kesulitan dalam Berkomunikasi dengan Siswa}

Anggapan guru matematika "galak" dan "Menakutkan" bagi siswa sehingga menampakkan matematika merupakan pelajaran yang sulit menjadi hal yang harus diperhatikan. Persoalan yang terpenting adalah bagaimana supaya siswa senang dan nyaman ketika belajar matematika. Komunikasi merupakan salah satu jawaban agar siswa bisa lebih menghargai guru tanpa ada perasaan takut dan terpaksa. Untuk lebih jelasnya, lihat tabel dibawah ini.

Tabel 3. Kesulitan dalam Berkomunikasi dengan Siswa

\begin{tabular}{|c|l|l|c|c|}
\hline No. & \multicolumn{1}{|c|}{ Kesulitan } & \multicolumn{1}{|c|}{ Sebab } & Jumlah & Persentase ( \% ) \\
\hline 1 & $\begin{array}{l}\text { Membantu } \\
\text { menumbuhkan } \\
\text { kepercayaan diri siswa }\end{array}$ & $\begin{array}{l}\text { Tidak bisa } \\
\text { matematika dan takut } \\
\text { salah }\end{array}$ & 3 & 42,85 \\
\hline 2 & Merangsang minat siswa & $\begin{array}{l}\text { Matematika sulit, } \\
\text { tidak menarik }\end{array}$ & 3 & 42,85 \\
\hline 3 & $\begin{array}{l}\text { Menumbuhkan sikap } \\
\text { positif } \\
\text { Terhadap matematika }\end{array}$ & $\begin{array}{l}\text { Siswa susah } \\
\text { memahami }\end{array}$ & 1 & 14,28 \\
\hline \multicolumn{2}{|c|}{ Total } & $\mathbf{7}$ & $\mathbf{1 0 0}$ \\
\hline
\end{tabular}

Dari tabel diatas dapat diketahui bahwa sebagian besar guru matematika mengalami kesulitan dalam merangsang minat siswa terhadap pelajaran matematika, karena matematika oleh kebanyakan siswa dianggap sulit dan tidak menarik. Kesulitan berikutnya adalah membantu menumbuhkan kepercayaan diri siswa, penyebabnya karena siswa merasa tidak bisa dan takut salah jika mengerjakan soal. Berbagai kesulitan guru matematika menurut analisis di atas sudah menjadi perhatian juga bagi Kepala Sekolah dalam meningkatkan cara kerja dan mutu guru. Dari hasil wawancara Kepala Sekolah, Kepala Sekolah selalu memotivasi guru matematika untuk meningkatkan kinerjanya, menyarankan ikut program MGMP, dan selalu diskusi dengan teman sejawatnya. 
Solusi yang dapat ditawarkan untuk mengatasi kesulitan guru, antara lain:

a. Seorang guru matematika seharusnya mempunyai keterampilan khusus agar bisa menambah minat siswa terhadap matematika dan tidak terkesan monoton dalam menyampaikan materi karena dalam setiap materi belum tentu dapat menggunakan media yang sama. Apabila media atau alat peraga tidak ada, maka guru haruslah kreatif untuk membuat sendiri alat peraga itu dan menciptakan media yang bagus sehingga menarik minat siswa terhadap matematika. Media pembelajaran memang penting diketahui karena tidak semua guru memahami bahwa:

1) Memiliki media pengajaran yang tepat akan dapat ditekan serendah-rendahnya semua hambatan komunikatif dalam setiap proses pembelajaran.

2) Anak didik dapat belajar atau menerima materi secara efektif sesuai dengan kemauannya.

3) Dengan menggunakan aneka ragam media pengajaran, tentunya secara efektif sekali, pengalaman dan cakrawala akan dapat diperluas.

b. Menciptakan kondisi pembelajaran yang dapat mencapai tujuan pembelajaran matematika. Dimana kondisi yang dimaksud adalah kondisi yang dapat membuat siswa belajar dengan nyaman dan tenang walaupun kondisi ruang kelas yang terbatas ataupun sempit.

c. Guru harus merangsang minat siswa terhadap pelajaran matematika dan membantu menumbuhkan kepercayaan diri siswa, Upaya guru matematika menumbuhkan minat ini banyak dilakukan, diantara upaya itu adalah.

1) Menjelaskan bahwa matematika merupakan ilmu yang membiasakan kita berfikir dan menganalisa permasalahan.

2) Menjelaskan bahwa matematika merupakan pelajaran yang menjadi kunci keberhasilan

3) Memberikan contoh matematika yang dapat diaplikasikan dalam kehidupan sehari-hari

4) Memberikan arahan bahwa matematika tidaklah sulit dan matematika banyak manfaatnya

5) Menjadi guru matematika yang rileks, tidak galak, dan menciptakan suasana belajar yang ceria

\section{KESIMPULAN}

Berdasarkan hasil penelitian yang telah di uraikan, dapat ditarik beberapa kesimpulan, antara lain, 1) Dalam merencanakan proses pembelajaran, kesulitan yang paling sering terjadi adalah menentukan media pembelajaran (25\%) dan selanjutnya menetukan metode mengajar $(18,75 \%)$ dll. Penyebab kesulitan ini adalah terbatasnya sarana prasarana dan media yang tak terjangkau oleh siswa serta guru kebingunan metode apa yang tepat untuk proses pembelajaran pada saat itu. 2) Dalam proses pembelajaran matematika, kesulitan yang paling sering terjadi adalah memotivasi siswa untuk bertanya $(44,44 \%)$ dll. Penyebab kesulitan ini adalah siswa menganggap matematika itu pelajaran yang kaku, sulit tidak mengasyikkan serta ketidaktahuan siswa terhadap hubungan materi matematika dalam kehidupan sehari-hari. 3) Dalam berkomunikasi dengan siswa, kesulitan yang paling sering terjadi adalah merangsang minat siswa terhadap pelajaran matematika $(42,85 \%)$ 
disebabkan karena kebanyakan siswa menganggap matematika pelajaran yang sulit dan tidak menarik.

\section{UCAPAN TERIMA KASIH}

Terimakasih yang tak terhingga kepada LPPM Universitas Pahlawan Tuanku Tambusai yang telah mewadahi penelitian ini sehingga penelitian ini dapat diselesaikan sebagaimana mestinya. Kemudian ucapan terimakasih juga disampaikan kepada mitra penelitian dalam hal ini adalah Sekolah Dasar Negeri 012 KP.Panjang Airtiris beserta anggota dan semua pihak yang telah membantu demi terselesaikan penelitian ini.

\section{REFERENSI}

Anitah, Sri W. (2008). Strategi Pembelajaran Matematika. Universitas Terbuka.

Arikunto, Suharsimi. (2000). Pengelolaan Kelas dan Siswa. Bandung: Sinar Baru Algesindo.

Badan Penelitian dan Bimbingan. (2001). KBK Mata Pelajaran Matematika SD. Jakarta: DEPDIKNAS.

Degeng, I Nyoman Sudan. (1997). Strategi Pembelajaran Mengorganisasikan Isi dan Model Elaborasi. Malang.

Erman Suherman, dkk. (1999). Strategi Belajar Mengajar Matematika. Jakarta: Universitas Terbuka.

Hadimiarso, Yusuf. (1993). Monograf Tehnik Pembelajaran. Jakarta: DepDikBud.

Hudoyo. (1990). Strategi Belajar Mengajar Matematika. Malang: IKIP Malang.

Ismail dkk. (2008). Kapita Selekta Pembelajaran Matematika. Jakarta: Universitas Terbuka.

Kunandar. (2008). Guru professional Implementasi KTSP dan Sukses dalam Sertifikasi Guru. Jakarta: PT Rajagrafindo Persada.

Margaret E. Bell Gretler. (1986). Belajar dan Membelajarkan, terjemahan Munandir. Jakarta: Rajawali.

Roestiyah NK. (1989). Masala-Masalah Ilmu Keguruan. Jakarta: PN. Bina Aksara.

Russeffendi. (1980). Pengajaran Matematika Modern Untuk Orang Tua Murid, Guru dan SPG. Bandung: Tarsito.

Sudjana, Nana. (1987). Cara belajar siswa Aktif. Bandung: PT. Sinar Baru.

Surakhmat, Winarno. (1979). Metodologi Pengajaran Nasional. Bandung: PN. Jemmars.

Tim Penulis PEKERTI. Hakekat Pembelajaran Matematika di Perguruan Tinggi: Jakarta: PAU- PPAI. Undang-undang Guru dan Dosen tahun 2006. Jakarta: CV Eka Jaya.

Zulkardi. (2001). RME: Teori, Contoh Pembelajaran, dan Taman Belajar di Internet "makalah Seminar $R M E^{\prime \prime}$. Bandung: UPI. 